\title{
Technologies of Attribution: Characterizing the Citizen-Consumer in
} Surveillance Performance

draft submitted to the International Journal of Performance Arts and Digital Media, special issue on Surveillance Technologies in Performance

\section{July, 2015}

the final article was published in November 2015, and is available from:

http://www.tandfonline.com/doi/full/10.1080/14794713.2015.1086134

\author{
Emily Rosamond
}

Goldsmiths, University of London 


\section{Abstract:}

Many accounts of surveillance and its subjective effects tend to focus on privacy. Along with this focus comes the assumption that surveillance's objects are simply facts and attributes, straightforwardly "mined" (or stolen) from people's private lives. Yet the habits and propensities ascribed to individuals through surveillance apparatuses are complex, relational phenomena: co-produced, selected and interpreted with interest by various actors. This essay begins to develop a critical language for surveillance as a form of characterization, by analyzing SWAMP's McService (2003), Hasan Elahi's Tracking Transience (2005-) and Erica Scourti's Life in AdWords (2012-2013). Following Sara Ahmed, I theorize characterization as a "technology of attribution" that attaches such interpretations of character to people within surveillant scenarios. Drawing from literary studies as well as recent work on the surveillance economy, I analyze the forms of attribution made possible within the surveillant scenarios in each of the artworks I analyze. Within these works, which span a decade between 9/11 and the Snowden revelations, one can trace an evolution of structures through which such attributions manifest: from self as threat, to self as set, to self as product.

\section{Full Text:}

In 2003, the art collective SWAMP ${ }^{1}$ (Doug Easterly and Matt Kenyon) videotaped themselves going through a McDonald's drive-thru fifty-seven consecutive times in Calera, Alabama (McService). The two artists order hotcakes, sausages, and other typical fast food in a perfectly usual way, recording footage as they go: the parking lot, McDonald's employees handing them food, their meals and receipts, their chewing mouths and chatting. Several hours into their performance, it becomes clear that their behaviour has aroused suspicion; two police cars intervene. "You know how people get kinda touchy," one of the officers intones, as he orders them not to go through the drive-thru again (SWAMP 2003).

\footnotetext{
${ }^{1}$ SWAMP stands for Studies of Work Atmosphere and Mass Production. It was founded in 1999 by Doug Easterly and Matt Kenyon, who worked together until 2012. Kenyon now runs SWAMP as a solo project.
} 
What, exactly, aroused suspicion, so much so that someone called the police? Ostensibly, the drive-thru customers were the perfect consumers: generating ample sales, enacting the most zealous and insatiable of appetites. Yet the pattern of their behaviour was irregular (or, more precisely, it was so regular that it is irregular: completely "normal" activities repeated to the point at which they become a hyperbolic caricature of consumption). Repeating an action to such an extent that it no longer finds a grounding logic in the body's appetites or in the routines of daily life normative expectations as to what should motivate behaviour - signals that there must be other, strategic considerations informing the action. (The police officer asks, “What are you gentlemen looking for? What's the prank, what's the joke?") (SWAMP 2003) The act of going through a drive-thru, unhinged from its usual motivations, acts as a sign of hidden, strategic motivation, the nature of which the actual act - going through the drive-thru in the usual way - reveals nothing.

What might these hidden motivations be? SWAMP's intentions appear to be largely analytical. They aimed to examine how the drive-thru siphons profits from local communities to international corporations, and produces a "regular pattern of information" as it does so:

Control regulated by mass marketing and mass production is exchanged at the window, with regular intervals of profit occurring throughout the day. Our performance, despite the fact that we spent almost $\$ 200$ in 5 hours, contradicted the semantics of this socioeconomic construct (SWAMP, McService).

McDonald's collects patterns of information from its customers, and not just money; their analyses of behavioural patterns impose far more exacting expectations on their consumers than simply that they spend as much money as possible. The artists seek to understand McDonald's' means of conceptualizing its customers. Yet these 
intentions, while they might be clear to viewers of SWAMP's documentation video, appear to be interpreted very differently by staff and police at the scene; SWAMP's action, thus, also explores the differential readings of a seemingly "illegible" act by various interested parties. To some, McService analyzes corporate semantics; to others, it incites the spectre of a security threat - even terrorist threat (the ultimate image of threat in post-9/11 American life). By creating a complex scenario of looking, McService activates a field of tensions between overlapping surveillance acts and apparatuses, each of which attributes characteristics to its subjects in different ways.

Further questions arise: in what ways, for instance, does corporate surveillance (McDonald's' interest in not only sales, but also who generates those sales) relate to police surveillance (which, in this case, seems aimed at pre-empting potential threats in response to citizen calls - even if its actual target ends up being consumer abnormality)? How do acts of citizen pre-emption (for instance, the employee who must have called the police to report SWAMP) relate to the counter-terrorist police apparatus? Consumerism and counter-terrorism: what do these two subspecies of surveillant motivation share, how do they diverge from one another - and how can their interconnectivity be felt, perceived and sufficiently analyzed in the complex relational milieus implicated in acts of surveillance?

In this paper, I argue that surveillance performances by SWAMP, Hasan Elahi and Erica Scourti suggest an analytical method through which to approach the complexities of multiple, overlapping perceptions of motivation in surveillance. These artists extend their interactions with surveillant apparatuses, in order to grasp something of how these apparatuses - with all their complex assemblages of actors, motivations and perceptions - envision their subjects. Their works suggest a theory of 
surveillance scenarios as sites of characterization. By characterization I mean complex, relational acts of attribution by which characteristics are ascribed to an object of surveillance, often based on some form of analysis of his/her propensities and patterns of behaviour (whether observed by people, through computational analysis, or with a combination of these). Characterization, the representational concept that best conveys how surveillance scenarios rely on the attribution and circulation of characteristics rather than their mere "discovery," highlights the fact that representations of surveillant subjects are not simply reflections of who that subject "is," but, rather, crystallize complex power relations between subject and state, and between consumer and corporation. Acts of characterization come into play in situations in which the relationship between a person's patterns of action and their motivation come into question. Analyzing surveillance performances through the lens of characterization highlights the disjunctions between various forms of surveillant motivation, which play out differentially in - and, indeed, as - representations of surveillant subjects. Characterization enacts a form of commerce between self, state, and corporate interest, allowing representations of personhood, behavioural pattern and tendency to circulate and accrue legitimacy and value.

McService, Elahi's Tracking Transience (2005-), and Erica Scourti's Life in AdWords (2012-13) span ten years (2003-2013) between 9/11 and the Snowden revelations. Given the rapid changes in surveillance practices and players within this decade, these three works represent a fertile range of apparatuses, monitoring practices and concerns, involving many actors, from citizens, to police, FBI agents, online users, corporations, self-documentarians and algorithms. While McService focuses on pre-emptive citizen reporting and extra-legal police measures, Tracking Transience documents Elahi's location and daily activities in obsessive detail online. 
Finally, Scourti's piece documents the artist keeping a daily diary, emailing it to her gmail account, and then reading out the AdWords Google's algorithms selected to match her consumer profile. Each of these works experiments with making its performer(s) visible as surveilled subjects; in a play of exaggerated docility, the performers produce acts of what could variously be read as curiosity about, empathy with, or even submission to their respective surveillance apparatuses, giving each apparatus what it seems to "want" (an anomaly; full transparency; and a fertile range of emotions and interests amenable to consumer desire, respectively). The performers' acts allow them (as well as their audience) to learn something about how such watchful eyes and sensors see. Through their complex, relational setups, these three pieces delineate an evolution, of sorts, between three different rhetorical structures through which surveillance-based characterization comes to be represented: from self as threat, to self as set, to self as product.

\section{$\underline{\text { Technologies of Attribution }}$}

What kind of person would go through a drive-thru fifty-seven times in a row? SWAMP's piece reveals the complexities with which the "character" of the involved actors comes into question, at moments in which an unusual behavioural pattern throws the relationships between action and intentionality into question. This focus, in fact, anticipated developments in surveillance practices and problematics that would become increasingly dominant - and increasingly automated - in the years to come. As Grégoire Chamayou notes, the National Security Agency's task - to distinguish benign from nefarious intention, within oceans of information - is inherently problematic: "What algorithm would be capable of detecting behavioural indices that could unmask this kind of intentionality?" $(2015$, p. 4). In spite of the Orwellian 
nightmares to which the NSA's seemingly all-knowing gaze (revealed to the public by Edward Snowden in 2013) might justifiably give rise, Chamayou notes that the NSA has been spectacularly ineffective in foiling terrorist plots, contributing nothing whatsoever to public safety throughout its entire telephone metadata collection program (p. 8). Just as the pre-emptive prohibitions on SWAMP's drive-thru activities, carried out by “touchy” McDonald's staff and police in a fear-gripped, post9/11 America, failed to distinguish between an analytical artists' project and a prospective terrorist plot, so the NSA's sophisticated surveillance apparatuses seem far more likely to produce presumed intentions than to uncover them lurking behind abnormal behavioural patterns. As an analyst of surveillance practices, how can one begin to develop a critical language for such acts, which involve the active selection and production of characteristics?

Of course, many critical responses to surveillance practices in the post-9/11 world take privacy as their central concern. While there are certainly important reasons to advocate the right to privacy, it is also necessary to point out privacy's limitations as a lens through which to analyze the complex, relational milieus of evershifting surveillance scenarios. ${ }^{2}$ As Mark Andrejevic writes, "Privacy debates... come to stand in for discussions that might more directly address the question of who controls the information infrastructure and for what ends" (2011, p. 279). Enacting customer loyalty in a surveillance economy, as SWAMP do in contracted fashion, involves fitting into corporate semantics, volunteering one's information along with one's cash. In a time of immensely concentrated wealth and power in the hands of a

\footnotetext{
${ }^{2}$ See, for instance, Dubrofsky and Magnet's feminist critique of whose bodies are routinely granted, or denied, the right to privacy $(2015$, p. 4$)$.
} 
few corporate, computational and financial players, ${ }^{3}$ opting out of such schemes comes at a price. Privacy, in the face of vastly privatized interests, becomes a pricey proposition.

Yet there is another fundamental, representational problem with the privacy debate. In painting images of governments and corporations peering into private lives, stealing traces of propensities, behaviours and intentions - seemingly traces of their subjects" "true selves" - privacy advocacy fails to account for the speculative nature of intentions and propensities in the first place. Whose suspicion, for instance, is reflected in the police's characterization of SWAMP as suspicious? The attribution of possibly nefarious intentions to the duo expresses complex speculations by various perceivers, as well as observed abnormalities in the actions of the perceived. Given this, and given the NSA's complete failure to discern intentionality in complex behavioural patterns, it is misleading to imply that the objects surveillance apparatuses seek are unearthed, pre-existing coordinates from private lives. Rather than viewing the attributive acts of surveillance as invasions of privacy (though they certainly may be facilitated by these), conceptualizing them as complex, relational, and speculative sites of characterization more aptly speaks to the sense in which the suspicious characteristics of surveillance subjects are not so much found as they are produced.

"Characterization" describes acts through which "character" comes to be perceived and represented; yet the latter's status as an object of study is far from uncontroversial. Even within literary theory, character has often been dismissed as an illusory, problematic and even conservative object of study. A generation of

\footnotetext{
${ }^{3}$ For an account of how the surveillance economy and how it concentrates wealth in the hands of a few businesses and financial players whose computational capacities can vastly outstrip their competitors, see Lanier (2014).
} 
structuralist literary theorists viewed character as a humanist illusion to be dismantled through criticism. ${ }^{4}$ More broadly, character has been, to many, merely a moralizing concept, associated with a conservative tendency to blame structural issues, such as poverty, on their victims. (That the poor might lack the "character" to succeed in the job market, for instance, is a self-fulfilling apology for gross structural and economic inequalities. ${ }^{5}$ ) However, it is precisely for these reasons that character - and the acts of characterization through which it comes to be produced, perceived and conceptualized - merit further study in an era of widespread speculation. With everproliferating surveillance apparatuses, which inscribe their subjects with characteristics in great detail and with a seemingly unquestionable realism, analyses of the complexities of attributions of "character" (a speculative, future-oriented, tendency-inscribed object par excellence) are incredibly urgent. Careful analyses of surveillance scenarios in which characterizations take place can denaturalize their ostensible realism, and reveal the complex interplays between individual lifespans and the actors (be they individuals, sensors, cameras, algorithms or complex combinations of these) that "read" them. Such interplays must navigate the tensions between a person's complexity and the relative simplicity of characterization's inscribed intentions; and between the "private" worlds of surveilled subjects and the ways in

\footnotetext{
${ }^{4}$ See, for instance, Deidre Shauna Lynch's critique of, on the one hand, the ahistorical approaches to literary character articulated by Ian Watt and his followers, and, on the other hand, the structuralist approaches associated with Roland Barthes, Alain Robbe-Grillet, Hélène Cixous and Colin MacCabe, in the introduction of The Economy of Character: Novels, Market Culture and the Business of Inner Meaning (1998, p. 4-16). Equally indicative of the widespread tendency to denigrate the concept of character is New Literary History's special issue on character (1974), of which Hélène Cixous' essay "The Character of 'Character"" is a prime example. As Rita Felski observes in her introduction to New Literary History's 2011 issue on character (its first since the 1974 issue), “The Character of "Character"' voiced a widespread sense among literary theorists that character survived only as a vestigial form. Tied to superannuated structures and coercive ideologies, it was a concept that seemed incapable of generating new knowledge" $(2011$, p. v). Despite the fact that character seemed so closed as a concept to literary theorists in 1974, Felski notes that several more recent studies, including Lynch's, have reanimated the concept, articulating a "conviction that literary character can disclose rather than disguise" (2011, p. v).

${ }^{5}$ For just one recent example of how writers have associated character with a right wing tendency to blame the poor for their poverty, see Giridharadas (2015).
} 
which that private experiences come to be represented and, as representations, shared through acts of observation.

As Sara Ahmed (2011) suggests in her study of "problem characters" in nineteenth-century novels, it is useful to think of character as an object determined by looking, as a glimpse: "it is not that we have a glimpse of character but that a character is a glimpse, [is] what creates an impression that there is someone being glimpsed" (p. 232). To characterize a person is to play with the impression that one has reduced her essential qualities, behaviours and propensities from a larger whole in an act of perception (and perhaps preconception), fabricated a smaller set of attributes that seem to aptly express the whole, while still sensing the limits of this smaller set as knowledge of the "whole" person. If this is so, then surveillance apparatuses such as the NSA's, which rely on vastly expanded data storage capacities, ${ }^{6}$ rewrite the relations between the total quantities of data collected and such productive acts of glimpsing, by expanding the palette of available information that can be used to characterize someone. As Edward Snowden put it, when asked why the average citizen should care about surveillance:

It's getting to the point, you don't have to have done anything wrong. You simply have to eventually fall under suspicion from somebody, even by a wrong call, and then they could use this system to go back in time and scrutinize every decision you've ever made, every friend you've ever discussed something with, and attack you on that basis, to sort of derive suspicion from an innocent life and paint anyone in the

\footnotetext{
${ }^{6}$ It should be noted that in May 2015, the U.S. House of Representatives passed the U.S.A. Freedom Act (by an overwhelming majority), which curbs the NSA's ability to collect phone metadata in bulk. This bill would seemingly limit the NSA's access to personal data, and thus its powers to characterize individuals, going forward. Yet as Shane Harris points out, this bill's passing has actually been viewed as a big win for the NSA within the intelligence community. The U.S.A. Freedom Act does not actually end the phone records program; it merely "requires that phone companies, not the NSA, hold onto the records" (Harris 2015). With just "a little more trouble," the NSA can still access all of the records, without having to shoulder the cumbersome and extremely expensive task of maintaining the databases themselves (Joel Brenner, former inspector general of the NSA, quoted in Harris 2015). The bill, arguably, merely outsources the NSA's data storage operations to the corporate sector.
} 
context [sic] of a wrongdoer. (Davidson, 2013; Greenwald et. al, 2013)

Deriving suspicion from innocent lives: Snowden's image aptly captures the sense in which characterization emerges out of complex and interested acts of selection and attribution. Given vast amounts of personal information to play with, characterization involves actively selecting palettes of facts and tendencies and painting with them, reconstructing representations of someone's character out of swaths of information, attributors' desires, perceptions, representational tropes, bureaucratic procedures, power relations, and computational capacities. As we will see in the next section, Hasan Elahi's self-surveillance project, a website on which he constantly updates his whereabouts and documents his activities, similarly navigates the tensions between vast quantities of personal data and their reduction through acts of characterization. (Yet, while Snowden articulates the dangers of a security agency having vast quantities of data with which to characterize its subjects, Elahi, as a victim of FBI racial profiling, uses vast quantities of self-generated personal data as a means of ensuring his security, correcting the FBI's bias.) With the capacity to analyze such vast quantities of data, algorithmic analyses can interpret their subjects' behaviours like never before. Yet in spite of any such conceit to realism - to adequately (could we say democratically?) represent the whole person from whom these few qualities have, somehow, become elected representatives - characterization is always (to use Ahmed's phrase), a "technology of attribution," an ascribed sense of self-fulfilling intentionality that "establishes 'the commerce' between reader and text" (2011, p. 233). If, as Ahmed suggests, such a description of characterization might be extended beyond the bounds of fictional worlds to describe relations between readers and characters, then surely it can also be repurposed as a fitting description of the 
commerce between surveillance apparatuses and their subjects, describing how characteristics are attributed and exchanged between various actors.

Characterization, as "technology of attribution," speaks to the ways in which tendencies to understand certain subjects as more "problematic" than others might be self-fulfilling. Racial profiling, of course, is a prime example of this. Elahi, along with millions of non-white people in the U.S. and elsewhere, know very well how pervasively and violently the state can differentially attribute suspiciousness according to racist preconceptions. ${ }^{7}$ Writing in the aftermath of yet another recent instance of police brutality against African-Americans (this time, an attack against teenagers at a pool party in McKinney, Texas), Sinthujan Varatharajah (2015) reflects on the pervasive internalization, for racialized subjects, of being characterized as a threat:

Growing up in white suprematist societies many of us have been conditioned to work hard to remain invisible... we grow up internalizing the criminalization of our bodies and are taught from childhood life-saving lessons to circumvent these macro- and microaggressions. It is these many little moments that accumulate throughout our lives when we, for instance, pull the seatbelt tighter when the cops drive by, when we dress in ways to not appear as threats, when we make sure that the supermarket bill is visible to not be considered looters, or when we choose to not call out racism (2015).

Varatharajah compellingly portrays how deeply internalized is the threat of constant characterization for non-white Americans, who must expend so much effort, day in and day out, simply to appear non-suspicious - or, rather, simply not to appear as a subject of interest.

\footnotetext{
${ }^{7}$ See, for instance, McClanahan on the laundering of racial bias in supposedly "objective" FICO ${ }^{\circledR}$ credit scores (2014, p. 47-48); Harcourt (2007) on racial profiling in predictive policing practices (both mentioned above); Dubrofsky and Magnet's emphasis on the ways in which new categories of racial identification are emerging in surveillance scenarios, such as the "terrorist look-alike" (2015, p. 9); and Chamayou's discussion of the use of racist sobriquets in NSA training material, as well as new forms of racial profiling emerging in the realm of big data analytics $(2015, \mathrm{p} .4)$
} 
Characterization, as a concept, covers both acts of attribution that are directly linked to preconceptions about race, sexuality and gender, and those that appear more minutely adapted to assess individual traits and propensities (even though these, of course, are by no means entirely separable from larger identificatory categories). Yet, while surveillance apparatuses can characterize anyone, it is important to remember that some bodies have a much harder time passing as unsuspicious than others. In a field of newly proliferating, automated and arguably correlative "technologies of attribution" - big data analytics, social media platforms and credit scoring innovations, for instance ${ }^{8}$ - characterization speaks to the active yet subtractive, perceptual and conceptual work of attribution, which actively creates characteristics to match preconceived problems. "Put simply," Ahmed writes, "when someone becomes a problem, we tend to question their character" (p. 233). Characterizing someone as a threat is contingent on a warp and woof of interests and biases that predetermine who - or what - counts as a problem.

\section{From Threat to Set: Character, Quantity and Spectres of Motivation}

Both SWAMP and Elahi examine these complexities. While SWAMP's piece speaks to the constitution of self as threat, Elahi's moves from self as threat to self as set. McService demonstrates, with elegant simplicity, how easily absurd repetition unhinges action from motivation. In this piece, the performers' actions have lost their legibility with respect to hunger and other motivating factors that would normally determine an individual's decision to go to McDonald's. Enjoyment, a reliable source

\footnotetext{
${ }^{8}$ For more detailed accounts of such developments and a discussion of their implications, see CheneyLippold (2011), Hallinan \& Striphas (2014), Gillespie (2012, 2014), Striphas (2010), Pariser (2011), Palmås (2011), Hearn (2010), McClanahan (2014) and Naughton (2014). I call such technologies "correlative" due to the fact that many forms of prediction and analysis associated with big data rely on detecting, and then cybernetically correcting, statistical correlations and rendering them actionable through prediction. Such developments aptly illustrate Deleuze's concept of "control societies" (one of the by now classic conceptualizations of the significance of computer-based, panspectric surveillance), which, in part, function by producing "dividuals" who are subject to statistical correlation (1992).
} 
of legible motivation, does not have a stable relationship to quantity; whereas one McDonald's meal might be enjoyable (to some), dozens in a row would surely not be. Their illegibility provokes terror, at the heart of post-9/11 life in the West, that quotidian actions to be détourned for nefarious purposes. The employees' decision to call the police can be understood as pre-emptive; it seeks to stop "vaguely suspicious" behaviour from escalating, manifesting a dangerous intention.

In the post-9/11 domestic security climate, character is the speculative object of pre-emption par excellence. As Brian Massumi (2007) has argued, there has been a wholesale shift toward pre-emption as an "operative logic of power" in contemporary politics and military tactics. Pre-emption, for Massumi, acts on a fundamental uncertainty in a world in which potential threats have not fully formed, and may not have even yet emerged. In order to fight a threat that has not yet emerged - is not yet knowable - it is best to provoke it into concrete existence. Snowden's image of “deriving suspicion from an innocent life," in light of Massumi’s argument, shows how characterization acts in tandem with pre-emptive logic. "Character" and characteristics (such as being "suspicious") are always speculative, and often selfaffirming objects; in McService's case, they are brought into being through fear as an affective agent through which potential future threats can act on the present. SWAMP's piece demonstrates how such indeterminately present futurity plays out in the sphere of domestic security in post-9/11 America, through citizen fear and extralegal police prohibitions.

If $M c$ Service speaks to the speculative creation of a threat simply through repetition unhinging action from intention, American artist Hasan Elahi's Tracking Transience (2005-) does just the opposite: it ameliorates threat through repetition. In 2002, Elahi was detained at the Detroit Airport on his way back from an exhibition in 
Amsterdam. Without knowing why he had come under suspicion (perhaps another with his name had been placed on a no-fly list?), he was held and questioned by the FBI for hours about the reasons for his frequent travels, whether he had visited any mosques, and whether he had moved explosives out of a storage unit. His familiarity with American culture, as well as showing the agents his Palm Pilot filled with records of gallery exhibitions, meetings and talks, eventually led to his release. He was subjected to lie detector tests, and required to check in with FBI agents for six months back in Tampa, where he lived at the time. How could he ensure that he would not be detained, or characterized as a threat, in the future? As he put it, "Once you're in the system, you're in... It's incredibly disturbing when a country, particularly your own country, uses discrimination as a basis for an investigation" (Scharper 2013).

In response to these experiences, Elahi began notifying the FBI whenever he left the country, in order to avoid hassles in airports. Eventually, this practice led him to launch Tracking Transience: the Orwell Project. On his website, www.trackingtransience.net (2005-ongoing), he frequently updates his location, and posts copious photographs of the scenes that comprise his everyday life: meals, highways, hallways, toilets, airports, gas stations, chain stores, and signs. The current version of the website begins with a homepage detailing his most recently entered coordinates with a flashing red arrow on top of a map and a scroll over a photo of the location. (The maps are produced in collaboration with the United States Geological Survey, which provides aerial surveillance images in response to his photographs' geographic coordinates.) (Creative Capital) Without warning, the page begins to flash through images (or whole subsets of images) from Elahi's life: perhaps an unmade 
bed in a hotel room, a nondescript watering hole, or a mosaic of small images of toilets or tacos compiled from various locations on various days.

Elahi's project responds to surveillance, yet without advocating for privacy in a straightforward way. Indeed, although he ostensibly gives up his privacy, Elahi claims to lead a very private life, in spite of - or even, given that he has pre-empted the FBI's targeting him, because of - constantly sharing its coordinates (Ashraf 2010). Rather, Elahi's work intervenes in the economy of surveillant information. As he puts it, "I share everything with the FBI - and everyone... Their currency is secrecy and access to information. Making information public devalues their currency" (Creative Capital). Given this analysis, we could say that Tracking Transience tackles privatization rather than privacy as such - it is not the individual's right to privacy that is the object of critique, so much as the ability of secrets (be they governmental or corporate) to generate value for some while they impoverish the power of others. Surveillance is part of an economy that garners value due to its being held privately, at an advantage over others; such value diminishes as soon as that information becomes public. If characterization establishes a commerce between a represented person and his/her "readers" (be these governmental agencies, corporate players or online user-citizens), then Elahi's project explores a way to enact that commerce differently, making his "character" more widely available so as to counter the privatization of his information-assets.

Further, Elahi's images of mass-produced objects, architectures and meals establish his "normalcy" as a consumer - but reveal little, if anything, of his thoughts, ideas or intentions. His images are sparse, unpopulated and banal. No friends or family come to view; there are only objects, meals, places and occasional passersby in the distance - a portrait of an alienated, consumerist life, rendered in the first person. 
The photographs bring to mind Ed Ruscha's series of deadpan portrayals of American locations (such as Twentysix Gasoline Stations, 1963). Like Ruscha's, Elahi's images seem to dissolve their own interest in spatial specificity. Presenting spatially specific phenomena as so many quantities overwhelms their specificity, draws attention to the tensions between the local and the non-local in these scenes. On trackingtransience.net, users witness mass-produced outputs of globalized corporate and financial circuits, whose origins, structures and workings are just as obscure to the casual observer as the inner workings of a surveillant subject's mind might be to the FBI (even when it has some help from citizens like Elahi, who correct at least some of its misattributions).

Unlike in Ruscha's project, Elahi (as target, referent, viewpoint, persona) remains the conceptual focus of the work, even as the specificity of his own life seems to disappear into an atmosphere of everyday artifacts. Focusing on his setting - the spaces and scenes of his life - he becomes a set, in the mathematical sense of "a collection of things (called its members or elements), the collection being regarded as a single object" (Enderton 1977, p. 1). Elahi appears as nothing more than the sum total of all locations, surroundings, activities and meals experienced (or, at least, indexed, evidenced), photographed and put into circulation by his website. He turns the cameras, becoming, in a sense, an empty container - nothing more than a firstperson perspective that links so many objects and environments. The sum total of these is his character, his represented being - but one which turns the focus away from his own particularity and onto the world he witnesses. Tracking Transience proposes the set as an alternative structure through which to represent character online - one which devalues privatized information currency, shifts the focus away from 
racialized bodies, and democratizes the weight given to each of Elahi's (often rather mundane) activities, eroding exceptions with tides of represented habits.

Tracking Transience seems ever more prescient, as today, droves of citizens routinely volunteer information about their activities, meals, and whereabouts on social media. Elahi's project acts on the faith that sharing information about so-called "private" life will, in a sense, de-privatize its information-flows, decrease its usefulness to government agents who only derive value from that to which they have privileged access. This is certainly the case in some instances (in Elahi's case, the public's witnessing his project tempers the FBI's singular hold on characterizing him as "threatening" or "non-threatening"). That said, there are also a host of recent developments in big data analytics that allow corporations to benefit from users' free sharing of personal information online.

\section{$\underline{\text { Life in AdWords }}$}

London-based artist Erica Scourti examines some of these developments, which make newly automated forms of characterization possible. For almost a year (March 2012 - January 2013), she emailed her daily diary to her gmail account, to see what kinds of AdWords would come up. She then "performed to webcam the list of suggested keywords linking to clusters of relevant ads" (Scourti 2013a). This process resulted in deadpan readings of disjointed, generic yet oddly personal clusters of words and phrases, at times hilariously at odds with her webcam-recorded image as a lived being-in-time. As she reads (often, it appears, in her bedroom at home, dressed casually, and at times accompanied by a black and white cat), the keywords settle in clusters on varying aspects of her activities, emotions, musings and social roles. Some of the keyword clusters relate to generic experiences that reveal more about the time 
of year (and how it is feted by large groups of people) than about Scourti herself. "New Year's eve. Drank. Drank too much. Fireworks. Good wishes for New Year," begins her January 2013 AdWords compilation (2013b). Other keyword clusters offer glimpses of her interests and concerns as an artist; MFA degree programs, London galleries and shipping solutions all feature. Still other keywords seem to speak to consumer concerns - prospective spending habits or online searches (for song lyrics or friendship poems, for instance); and to health and physical ailments (severe sore throats, or the benefits of drinking water). Finally, there are those keywords that touch on subjects typically coded as private, and even "internal:" anxieties, stress, depression, emotions, love and relationships. Essential to each of these provisional categories is a rhythmic ebb and flow that sees them waft in and out of each other's purview, loosely weaving together scraps of separate activities, anxieties and aspects of identity. In her March 2012 compilation, she recites: "Lyrics lyrics. Feeling tired. Always feeling sad. Feeling depressed. Healthy eating food. Music and lyrics. Eating out. Song lyrics." And the next day, slumped in bed, she reads: "Love relationship. Love relationships. Love and romance. Severe sore throat. Lyrics lyrics. Anxiety and depression. Anxiety and stress. Depression and anxiety" (Scourti 2012a). The keywords circulate feelings, interests and concerns, quite literally, as commerce in an attention economy, in which companies pay for the privilege of having their websites stand out from millions of others by competing in keyword auctions. What substantiates these keywords' claim to value is that they are hinged on algorithmic "readings" of the individual online user and, thus, ostensibly closely reflect her expressed habits, interests and concerns - her character.

That habits shape character is certainly nothing new. In The Gay Science (first published in 1882), Nietzsche remarks that when someone has worked the same job 
for several years, he in effect becomes the character he once merely played (1974, p. 302). From playing to being: character is that which stiffens through work, repetition and time. What is the analogous scenario to Nietzsche's in an era of immaterial labour, in which an "alienated cognitariat" (as Franco "Bifo" Berardi [2010] calls it) drifts from job to job, task to task, contract to contract? The keywords algorithms that Scourti's piece reveals highlight at least two new means through which habits stiffen into representations of character in the surveillance economy. On the one hand, the concept of the working self, here, extends beyond the traditional, liberal-era realms of work to encompass consumer behaviour, entrepreneurial activities associated with landing art projects, the emotional labour of maintaining personal relationships, and the like. One's character encompasses more than simply a particular role one plays in a specific context; it blends work, consumption, personal life and entrepreneurialism, navigating the tensions between all of these roles and conceptualizing each of them as, in some sense, equal forms of immaterial labour. On the other hand, the automaticity and ubiquity of such readings reifies the rhythmic flux and flow of habits, interests and concerns, making their stiffening into representations of "character" through algorithmic analysis a matter of course. Yet neither of these statements go far enough; for there has also been a complete reversal. The worker for all her precarity, her anxieties, her endless mixing of heterogeneous tasks and social roles - becomes a product, whose attention, tendencies and even identities are sold to Google's corporate clients.

As Christian Fuchs writes, “Google commodifies users' cognition, communication and cooperation by engaging in surveillance of these activities, creating data about them and selling these data to advertising clients" (Fuchs 2011). Google AdWords, a primary agent of this political economy, is based on an auction 
system through which advertisers compete for prominent screen positions with respect to keywords linked to specific users (Fuchs 2011; Girard 2009, p. 31). While Google may well be a pioneer in selling such specificities to advertisers, it encompasses only one amongst a host of recent developments in monetized online surveillance. John Cheney-Lippold (2011) refers to some such developments in his work on algorithmic identity production, which he understands as a form of "soft biopolitics." He describes the online data collection practices of, for instance, the Quantcast corporation - one of many companies that provides audience measurement services for member websites, thus helping them to best target advertisements to individual IP addresses. Based on browsing history, one of Quantcast's algorithms might decide that in individual user is, for instance, male. Maleness emerges as a trait, in Quantcast's formulae, purely numerically, without any reference to the user's embodied identity.

Yet, conversely, the identifications at which the algorithms arrive self-modify in a cybernetic loop, sometimes overturning or modifying the initial assumptions that led to a particular identification being made in the first place. In the process, CheneyLippold argues, "the regulation of gender as a category... becomes wholly embedded within the logic of consumption, where categorical behaviours are statistically defined through a cybernetics of purchasing and research that marketers have deemed valuable for identification and categorization" (p. 171). This new algorithmic identity, Cheney-Lippold argues, operates at a distance from traditional liberal politics, and enacts a form of control best understood according to Deleuze's concept of modulation (1992), which "configures life by tailoring its conditions of possibility," rather than directly disciplining subjects (p. 169). As online identification apparatuses constantly - and automatically - characterize users based on their consumptive and affective labour, they shape users' potential future online experiences along the same 
lines as their characterizations, thus actively closing the loop between characterization and subjectivation.

Scourti's piece stages a dialogue between two descriptive technologies for representing complex, interior life (one very old, the other quite recent): the diary (as a form of becoming-character through self-representation) and its algorithmic analysis (an apparatus that characterizes). As she continually reads her AdWords, a double pedagogical process takes place. She "teaches" Google's algorithms to recognize her more efficiently - to translate diaristic interiority into algorithmic interiority. In doing so, she learns something of how these algorithms see; as she reads out her keywords, it is almost as if she is learning how to speak their language. ${ }^{9}$ This language wrests interests, doubts and desires into clouds of tendencies. Scourti's actions point to the cybernetic feedback loops at the heart of a newly emerging "political economy of propensity" (Thrift 2009) ${ }^{10}$ articulated, in large part, through data analytics companies, online advertisers and social media platforms. These apparatuses analyze older modes of documenting interior complexity (for instance, letter writing reconfigured as email), in real time, in hopes of securing future value in the present. In her May 2012 compilation of AdWords, Scourti speaks to such concerns in the language of AdWords' algorithms: "Relaxation techniques for anxiety. Predict future. Tell me my future. I want to know my future" (Scourti 2012b). This string of

\footnotetext{
${ }^{9}$ Ted Striphas' work helps to conceptualize this dialogue further (Hallinan and Striphas 2014; Striphas 2012; Granieri 2014). His term "algorithmic culture" describes the ways in which algorithms increasingly do traditional "cultural" work: "of the sorting, classifying, and hierarchizing of people, places, objects, and ideas" (Granieri 2014). For instance, Google and Facebook use algorithms to determine what appears in a specific user's search engine.

${ }^{10}$ As Thrift (2009) argues, there is a newly emerging "political economy of propensity" in contemporary societies, the outlines of which have yet to be entirely written. Propensity, he argues, should be "understood jointly as both a tendency-cum-attraction and an innate inclination, that is, as a disposition to behave in a certain way which is only partly in control of the agent" (p. 83). Extending Thrift's work, we could say that the ever more ubiquitous predictive and pre-emptive practices of algorithmic surveillance (or dataveillance, as Van Dijck, 2014 prefers to call it) trade in propensity, routinely produce and monetize its images out of desires, disturbances and moods that are partly personal, and partly expressions of "imitative rays" of shared interests, feelings and behaviors that spread through social networks.
} 
AdWords seems meant to appeal to the "personal" anxieties about the future attributed, by algorithms, to Scourti; yet perhaps they speak even more loudly to how such anxieties (be they actual or invented through analysis) have fallen into lockstep with the surveillance apparatuses' own preoccupations with prediction, propensity, risk assessment and producing value through these. If Elahi's piece represented character as a set of indexed habitual experiences and tendencies in order to devalue the highly anomalous attributions to which he had been subjected by the FBI, then Scourti's piece grapples with the commercialization and normalization of characterization through the analysis of precisely such rhythms of habits and tendencies. Scourti's piece analyzes a structure of characterization as a cybernetic feedback loop in which algorithmic analyses of her tendencies align with and shape the personal desire for self-actualization ${ }^{11}$ in complex ways.

\section{Characterizing Differently? Toward a Critical Language of Attribution}

With each surveillant act of characterization comes a complex expression of the interplay between a surveillance apparatus and the "character" of its subject. Several actors' and apparatuses' inclinations, perceptual capacities, economic interests, presuppositions and desires actively shape how a characteristic can come to be attributed to its character. Scourti's project clearly demonstrates this by setting up a nuanced, ongoing dialogue between her self-reflection through writing and the algorithms that track her, amplifying certain doubts, desires and consumer interests over others and transforming these into monetized attention-lures. Elahi's project takes the FBI's desire for his transparency to an extreme, and sees its subject dissolve

\footnotetext{
${ }^{11}$ Self-actualization, in itself, can be understood as a form of neoliberal governmentality. As Michel Feher (2009) argues, concepts of self-appreciation are inextricably linked to the emergence of the concept of "human capital" in the mid-twentieth century, which initially referred to "the set of skills that an individual can acquire thanks to investments in his or her education or training" (p. 25).
} 
into a haze of locations, habits and objects that open surveillance onto other forms of witnessing and self-characterization. While Elahi's website inscribes - and protects his lifespan with a "safe" range of represented, repetitive habits and tendencies, SWAMP uses repetitive, habitual behaviour against the grain, as (to use Massumi's

term) “threat-o-genic.” Repeated behaviours, in SWAMP's setup, unmoor action from intention, throwing character into question. All of these projects establish character as a vitally important, speculative object of surveillance. Characteristics belong to no one person, since they are always attributed relationally; as such, their problematics are those of privatization (which determines which actors have the representational power to attribute characteristics to others most forcefully within a given surveillant milieu), rather than of privacy.

SWAMP, Elahi and Scourti provide insightful studies of these emerging dynamics. In doing so, their projects also suggest that an adequate response to contemporary surveillance involves developing new criteria for characterization: a critical language for the ways in which characteristics can be selected, elected and coproduced from available data sets and tendencies by various interested parties. Such a language could speak far more pointedly than privacy to the aesthetic and speculative dimensions of surveillant citizenship, in an era in which representations of individuals' futurity have ever more influence on their present.

\section{$\underline{\text { Acknowledgments }}$}

I would like to thank Elise Morrison and the two anonymous peer reviewers for their insightful comments, which greatly contributed to this paper.

\section{Bibliography}


Ahmed, S. (2011) "Willful Parts: Problem Characters and the Problem of Character." New Literary History 42(2): 231-253.

Andrejevic, M. (2011) "Surveillance and Alienation in the Online Economy." Surveillance \& Society 8(3): 278-287.

Ashraf, H. (2010) "Professor Hasan Elahi: 'I Can Watch Myself a Lot Better than They Ever Could." Patheos [Online]. Available at:

http://www.patheos.com/blogs/altmuslim/2010/05/i_can_watch_myself_a_lot_better_ than_they_ever_could/[Accessed 20 May 2015].

Assange, J. (2014) "Google is Not What it Seems." Newsweek. 23 October. [Online] Available at: http://www.newsweek.com/assange-google-not-what-it-seems-279447. [Accessed 19 November, 2014.]

Berardi, F. (2010) "Cognitarian Subjectivation". e-flux 20. (Online) Available at: http://www.e-flux.com/journal/cognitarian-subjectivation/ [Accessed 10 October 2014]

Bratton, B. (2014) “The Black Stack". e-flux 53. [Online] Available at: http://www.eflux.com/journal/the-black-stack/. [Accessed 27 May 2014].

Chamayou, G. (2015) “Oceanic Enemy: A Brief Philosophical History of the NSA.” Radical Philosophy 191: 2-12.

Cheney-Lippold, J. (2011) "A New Algorithmic Identity: Soft Biopolitics and the Modulation of Control." Theory, Culture and Society 28:6: 164-181.

Cixous, H. (1974) “The Character of Character.” Trans. Keith Cohen. New Literary History 5(2): 383-402.

Clarke, L. (2007) “Thinking Possibilistically in a Probabilistic World”. Significance, a Journal of the Royal Statistical Society, 4(4): 190-192.

Creative Capital. "Hasan Elahi, Tracking Transience: The Orwell Project." [Online] Available at: http://creative-capital.org/project_contexts/view/10/project:48 [Accessed 20 May 2015].

Daniel, C. and Palmer. M. (2007) “Google's Goal: To Organize Your Daily Life”. Financial Times. 22 May. http://www.ft.com/intl/cms/s/2/c3e49548-088e-11dc-b11e000b5df10621.html\#axzz3JVBqeAqk. [Accessed 19 November 2014.]

Davidson, A. (2013) "Edward Snowden, the NSA Leaker, Comes Forward". The New Yorker, 9 June 2013, http://www.newyorker.com/online/blogs/closeread/2013/06/edwardsnowden-the-nsa-leaker-comes-forward.html. (Accessed 27 May 2014.)

Deleuze, G. (1992) "Postscript on the Societies of Control”. October 59: pp. 3-7.

Dubrofsky, R. and Magnet, S.A., eds. (2015) Feminist Surveillance Studies. Durham: Duke University Press. 
Dunkley. E. (2014) “Will You Pass UK Lenders' Tough New Mortgage Test?” Financial Times, 25 April, http://www.ft.com/cms/s/0/f5443022-ca32-11e3-bb92-

00144feabdc0.html\#axzz32vElIRUF. (Accessed 27 May 2014.)

Elahi, H. (2015) Tracking Transience v2.0. [Online] Available at: http://elahi.umd.edu/track/ [Accessed 14 January 2015].

Enderton, H. B. (1977) Elements of Set Theory. New York: Academic Press.

Feher, M. (2009) "Self-Appreciation; Or, the Aspirations of Human Capital." Trans. Ivan Ascher. Public Culture 21:1, 21-41.

Foucault, M. (2008) The Birth of Biopolitics: Lectures at the Collège de France 1978-79. Ed. Michel Senellart. Trans. Graham Burchell. New York: Palgrave Macmillan.

Fuchs, C. (2011) "A Contribution to the Critique of the Political Economy of Google." Fast Capitailsm 8(1) [Online]. Available at: http://www.uta.edu/huma/agger/fastcapitalism/8_1/fuchs8_1 [Accessed 15 May 2015].

Fuchs, C. et al., eds. (2012) Internet and Surveillance: The Challenges of Web 2.0 and Social Media. New York: Routledge.

Gillespie, T. (2012) “Can an Algorithm be Wrong?” Limn 2, http://escholarship.org/uc/item/0jk9k4hj. (Accessed 25 August 2014)

Gillespie, T. (2014) “The Relevance of Algorithms”. In Media Technologies, ed. Pablo Boczkowski, Kirsten Foot, Tarleton Gillespie. Cambridge: MIT Press.

Girard, B. (2009) The Google Way: How One Company is Revolutionizing Management as we Know It. San Francisco: No Starch Press.

Giridharadas, A. (2015) "Want a Steady Income? There's an App for That." New York Times, April 29 [Online]. Available at: http://www.nytimes.com/2015/05/03/magazine/wanta-steady-income-theres-an-app-for-that.html?smid=fb-share\&_r=1 [Accessed 10 June, 2015].

Granieri, G. (2014) “Algorithmic Culture. 'Culture now has two audiences: people and machines"” (Interview with Ted Striphas.) Medium [Online] Available at: https://medium.com/futurists-views/2bdaa404f643. (Accessed 4 May 2014)

Greenwald, G., MacAskill, E., and Poitras, L. (2013) "Edward Snowden: The Whistleblower Behind the NSA Surveillance Revelations". The Guardian, 11 June, http://www.theguardian.com/world/2013/jun/09/edward-snowden-nsa-whistleblowersurveillance. (Accessed 27 May 2014.)

Groys, B. (2008) Art Power. Cambridge, MA: MIT Press.

Groys, B. (2005) “The Fate of Art in the Age of Terror." In Making Things Public: Atmospheres of Democracy, ed. Bruno Latour and Peter Weibel. Cambridge, MA: MIT Press: 970-5.

Hallinan, B. and Striphas, T. (2014) "Recommended for You: the Netflix Prize and the Production of Algorithmic Culture." New Media and Society: 1-21. 
Harcourt, B. (2007) Against Prediction: Profiling, Policing and Punishing in an Actuarial Age. Chicago: University of Chicago Press.

Harris, S. (2015) “"Big Win' for Big Brother: NSA Celebrates the Bill that's Designed to Cuff Them." The Daily Beast, May 14. [Online] Available at:

http://www.thedailybeast.com/articles/2015/05/14/nsa-loves-the-nothing-burgerspying-reform-bill.html [Accessed 10 June, 2015].

Hearn, A. (2010) "Structuring Feeling: Web 2.0, Online Ranking and Rating, and the Digital 'Reputation' Economy”. ephemera 10 (3/4): 421-438.

Lanier, J. (2014) Who Owns the Future? New York: Simon \& Schuster.

Latour, B. and Lépinay, V. A. (2009) The Science of Passionate Interests: an Introduction to Gabriel Tarde's Economic Anthropology. Chicago: Prickly Paradigm Press.

Lazzarato, M. (2012) The Making of Indebted Man: An Essay on the Neoliberal Condition. Amsterdam: Semiotext(e).

Martin, R. (2002) Financialization of Daily Life. Philadelphia: Temple University Press.

Martin, R. (2012) “A Precarious Dance, a Derivative Sociality”. TDR: The Drama Review 56(4): 64-79.

Massumi, B. (2007) "Potential Politics and the Primacy of Preemption". Theory \& Event 10(2), https://muse.jhu.edu/journals/theory_and_event/v010/10.2massumi.html. (Accessed 15 July 2014.)

McClanahan, A. (2014) "Bad Credit: The Character of Credit Scoring". Representations 126:1, pp. 31-57.

Morozov, E. (2011) The Net Delusion: The Dark Side of Internet Freedom. New York: Public Affairs.

Morozov, E. (2013) To Save Everything, Click Here: The Folly of Technological Solutionism. New York: Public Affairs.

Naughton, J. (2014) “We're All Being Mined for Data - but Who are the Real Winners?" The Guardian, 8 June, http://www.theguardian.com/technology/2014/jun/08/big-datamined-real-winners-nsa-gchq-surveillance?CMP=fb_gu. (Accessed 10 June 2014.)

Ngai, S. (2012) Our Aesthetic Categories: Zany, Cute, Interesting. Cambridge, MA: Harvard University Press.

Nietzsche, F. (1974) The Gay Science. Translated by Walter Kaufman. New York: Vintage Books.

Nitzan, J. and Bichler, S. (2009) Capital as Power: A Study of Order and Creorder London: Routledge.

O’Donnell, C. (2014) "Getting Played: Gamification, Bullshit, and the Rise of Algorithmic Surveillance.” Surveillance \& Society 12(3): 349-359. 
Palmås, K. (2011) "Predicting What You'll Do Tomorrow: Panspectric Surveillance and the Contemporary Corporation". Surveillance and Society 8 (3): pp. 338-354.

Pariser, E. (2011) The Filter Bubble: What the Internet is Hiding From You. New York: The Penguin Press.

Scharper, J. (2013) “Artist Hasan Elahi Meticulously Documents Life After FBI Investigation.” The Baltimore Sun. 22 January. [Online] Available at: http://articles.baltimoresun.com/2013-01-22/news/bs-md-um-professor-art20130117_1_fbi-agent-storage-unit-documents-life [Accessed 13 January, 2015].

Scourti, E. (2012a) Life an AdWords: March 2012. [Online] Available at: https://vimeo.com/album/1944360/video/39677781 [Accessed 17 May 2014].

Scourti, E. (2012b) Life an AdWords: May 2012. [Online] Available at: https://vimeo.com/album/1944360/video/43392648 [Accessed 17 May 2014].

Scourti, E. (2013a) Life in AdWords. [Online] Available at: https://vimeo.com/album/1944360. [Accessed 17 May 2014].

Scourti, E. (2013b) Life in AdWords: January 2013. [Online] Available at: https://vimeo.com/album/1944360/video/58777871. [Accessed 17 May 2014].

Smith, J. (2010) Grow Your Business with Google AdWords. New York: McGraw-Hill.

Striphas, T. (2010) "The Abuses of Literacy: Amazon Kindle and the Right to Read." Communication and Critical/Cultural Studies 7:3: pp. 297-317.

SWAMP (2003) McService. [Online] Available at: https://www.youtube.com/watch?v=pWOrKJF5fX0 [Accessed 14 January 2015].

“SWAMP, McService." Matt Kenyon's Studies in Work Atmospheres and Mass Production. [Online] Available at: http://www.swamp.nu/projects/mcservice/ [Accessed 16 May 2015].

Tarde, G. (2007) “Economic Psychology”. Translated by Alberto Toscano. Economy and Society 36 (4): 614-643.

Thrift, N. (2009) "Pass it on: Towards a political economy of propensity." Emotion, Space and Society 1(2): 83-96.

Van Dijck, J. (2014) "Datafication, Dataism and Dataveillance: Big Data Between Scientific Paradigm and Ideology." Surveillance \& Society 12(2): 197-208.

Varatharajah, S. (2015) "Hypervisible Bodies: Protesting White Supremacy Whilst Racialized." Media Diversified, June 12. [Online] Available at: http://mediadiversified.org/2015/06/11/hypervisible-bodies-protesting-whitesupremacy-whilst-racialised/ [Accessed 12 June, 2015]. 